\title{
And on gloomy Sunday...
}

There goes the neighbourhood.

\section{Anthony S. Haines}

Dave rang the doorbell of the small terraced house. After a few moments, a man in a dressing-gown opened the door.

"Hello, I'd like to talk to you about God," Dave began.

"Sure," the man interrupted. "What would you like to know about me?"

After a few moments of confusion, Dave's mind-wave collapsed to a plausible model, and he said: "I'm sorry, I've never met anyone actually called God before."

"No," said the man. "I meant I am the creator of your universe. Why don't you come in?"

Dave mutely followed God into his dingy apartment. "How can I know you are God?" he wondered aloud.

"Really," said God. "I thought you were the one to work on faith. But I don't have time to argue the point. Here, taste this." He handed Dave a glass of clear liquid. A sip told Dave that it was water. "Now try it again." The liquid was now red, and tasted of wine. "An old favourite, but these days a mere parlour trick, perhaps? Try this on for size." Suddenly, Dave was standing in a field of flowers, under an azure sky. "Before you ask; no this isn't heaven," said God. "It's Devon."

A moment later they were back in God's living room. "Would you like to sit down? I'll make you a cup of tea."

"Why have you revealed yourself to me?" Dave asked while God rinsed out a pair of grubby-looking mugs.

"You came to me, remember? And I thought - why not? Let me explain my problem. Your philosophers have struggled with the existence of the world for a long time. But the truth is that it was an accident. I invented a way of representing a simple universe using much less processing than normal. You'll have heard of cellular automata? It's something like that. Quantum mechanics is in there to reduce the processing load.

"Anyway, after a bit of tweaking of the parameters, interesting stuff started to happen. I got atoms, molecules, stars, everything. And, eventually, life arose - here and there, where conditions were just right. Just three usable dimensions, and all of this..." God looked misty eyed for a moment. "Then, suddenly, wham! The speed of time slowed right down. And looking into it I found this tiny planet where quantum effects had suddenly become much more intensive to process."

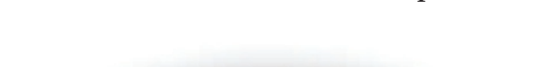

it in quite a respectable journal."

Dave's tea was untouched. "What are you doing here in Birmingham?" He asked.

"Oh, I've been watching for so long," God said. "I just wanted to see what this world felt like..."

God leaned forward. "Have you heard about memes? There are good ideas and bad ideas, and they are passed on almost independently of whether they are true. To be successful, an idea, that is, a 'meme', must be passed from brain to brain.

"Usually this happens because the carrier has benefited, and wishes to pass useful information on. But not always. Memes may persuade their host to propagate them. And unrelated memes can merge together, and may then transfer more effectively. This is what is happening when children whisper gossip to each other followed by the phrase 'and pass it on.

"Generally we think of ideas as little additions to the mind. But ideas affect the mind. I'm sure you'll have heard a song that you don't like but can't stop your brain from singing? What if something worse existed? Your literature is already sprinkled with stories about the concept: pictures that kill the viewer, games so addictive no one could stop playing; the format isn't important. And Douglas Hofstadter described how it is impossible to create a perfect gramophone, because if it reproduces every sound perfectly there will be a noise that destroys it.

"The same must be true of consciousness. So there is good reason to believe that lethal conceptually transmitted diseases can exist. And moreover, that they may be highly infectious, or have a carrier phase. Discovering you has led to something of a backlash I'm afraid. There are forces that even God must answer to. The Research Council has spoken. I have to switch your universe off."

As a microbiologist and hobbyist programmer, Tony Haines can create and destroy worlds both at work and in his spare time. 